\title{
Transpulmonary artery distance in patients with coal workers' pneumoconiosis
}

\author{
R. L. S A D LER \\ Pneumoconiosis Medical Panel, Swansea
}

\begin{abstract}
Correlation has been established between the size of the main pulmonary arteries, as seen on the postero-anterior radiograph, and the pulmonary artery pressure. In this study the distance between the bifurcations of the right and left pulmonary arteries, referred to as the transpulmonary artery distance (TPD), has been used as a measure of the size of these vessels. In 293 patients with simple pneumoconiosis TPD was significantly correlated with height but not with stem-height, age, weight or forced expiratory volume. The mean TPD of patients with simple pneumoconiosis with or without chronic bronchitis was similar. Among 367 patients with complicated pneumoconiosis those with early fibrosis (A shadows) had a mean TPD similar to that found in simple pneumoconiosis, but those patients with extensive fibrosis (B or C shadows) had significantly greater values. The pathological changes of pulmonary hypertension in complicated pneumoconiosis are reflected in these measurements.
\end{abstract}

Correlation between the size of the main pulmonary artery (as seen on the postero-anterior chest radiograph) and pulmonary artery pressure was reported by Moore et al. (1959), in which study the distance to the border of the main artery from the centre line of the chest was expressed as a ratio of the hemithorax diameter. Also using this measurement, Milne (1963) was able to predict pulmonary arterial pressures recorded at catheterization in patients with mitral stenosis: depending on its level, he was able to foretell within $10 \mathrm{mmHg}$ the pressure directly observed in $68 \%$ to $76 \%$ of patients. Hicken, Green, and Bishop (1968) obtained a high correlation between the transpulmonary artery distance (the distance between the bifurcations of the right and left main pulmonary arteries) and the pulmonary artery pressure in patients with chronic bronchitis.

Transpulmonary artery distance (TPD) was measured in chest radiographs (Fig. 1) of men with coal workers' pneumoconiosis in the present investigation. Patients with simple pneumoconiosis (391) were divided into those with and those without chronic bronchitis, the definition of the latter for this purpose being that of non-specific chronic lung disease (Ciba Guest Symposium, 1959). Of those without chronic bronchitis non-smokers formed a further group. Patients with complicated pneumoconiosis (367) were divided into groups $A$, $B$, and $C$, corresponding with the International
Classification of Radiographs (International Labour Office, 1970). The films studied were those of consecutive attenders at a pneumoconiosis panel in a period of six months (simple pneumoconiosis) or 12 months (complicated pneumoconiosis). The measurements of TPD, by use of geometric dividers, were made by one observer who recorded the average of three observations made at one session. The repeatability of such measurements has been demonstrated by Hicken et al. (1968), who showed that the differences in mean values of TPD in 42 normal subjects at three readings by one observer and in 42 cases with chronic bronchitis (where there was clearer definition of pulmonary arteries) did not exceed $1.8 \%$ and $0.2 \%$ of the mean TPD respectively.

The loss of precision introduced by the use of imperfect radiographs can be demonstrated. Where two radiographically excellent films in a series have identical TPD measurements, this measurement should remain the same in any films taken in the time interval between them. In such 'interval' films it was found that 64 were underpenetrated and had an error of $4.4 \%$ whereas 20 , in which rotation was apparent, had an error of $1.5 \%$ of the mean TPD.

In under-penetrated radiographs, main pulmonary arteries are sometimes overshadowed by the opacities of smaller vessels, making difficult an accurate identification of the main bifurcations; 


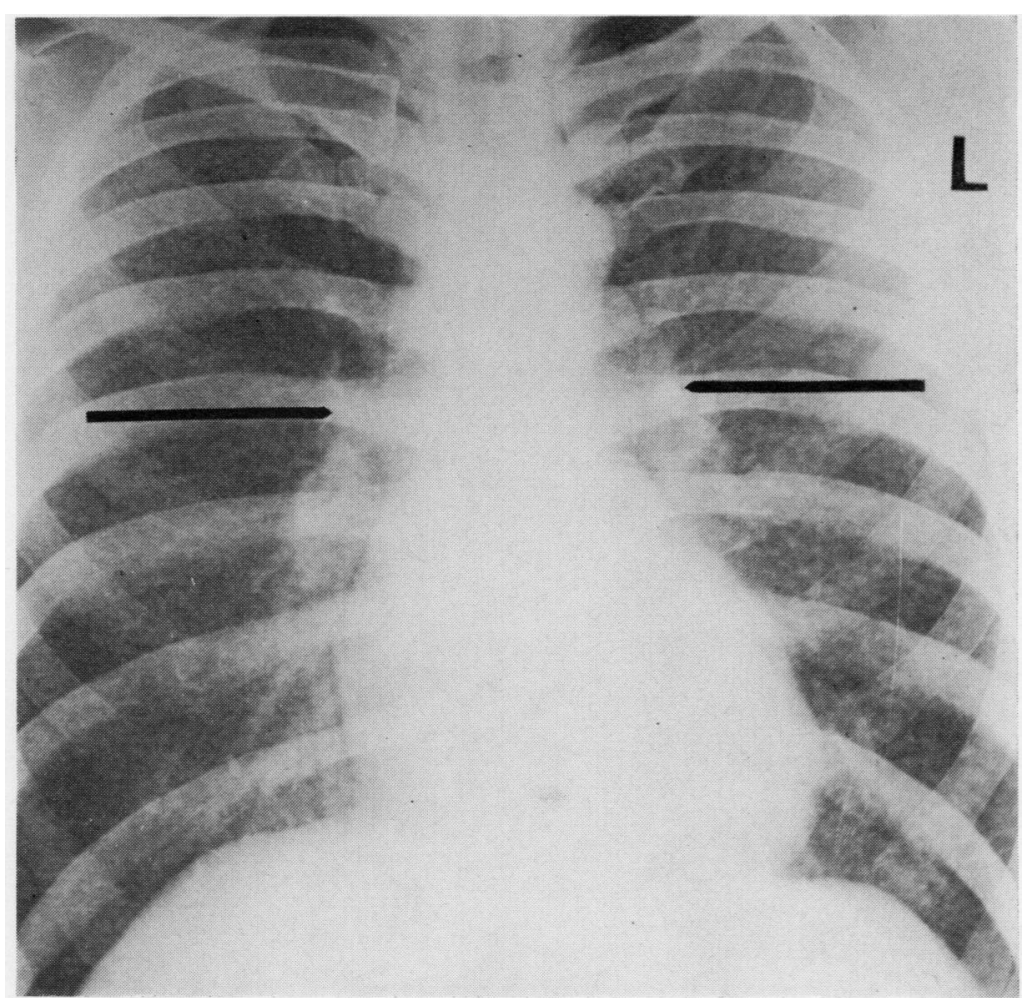

FIG. 1. Transpulmonary artery distance : bifurcations of right and left main pulmonary arteries indicated.

but rotation clearly shown by lateral displacement of a sternoclavicular junction may produce minimal effect on the positioning of pulmonary main arteries: sternoclavicular joints are peripheral structures while the arteries lie near to the chest's axis of rotation. Other radiographs in pneumoconiotic patients in which difficulty may arise are those showing marked hilar adenopathy or those in which massive fibrosis displaces or overlaps hilar structures (Fig. 2). To avoid these sources of error only radiographically excellent films in which hilar structures were clearly evident were used in the investigation.

The TPD was also measured in the last available film of 155 men with complicated pneumoconiosis who had died during the years 1967-70 and in whom the pneumoconiosis had been considered to be a material factor in causing death. In such patients, as well as in pathologists' necropsy reports, the descriptions of the hearts and lungs by the pneumoconiosis boards were available. In all these patients macroscopic examination of the perfused lungs had revealed centrilobular or pan- lobular emphysema as well as massive fibrosis. Taking $5 \mathrm{~mm}$ as the maximum normal thickness of the outflow tract, about half of them had right ventricular hypertrophy.

In the patients with simple pneumoconiosis without bronchitis correlation coefficients (r) were calculated between TPD and the following variables-height, stem-height, weight, age, and forced expiratory volume in one second $\left(F E V_{1}\right)$ expressed as a percentage of the expected value; in patients with simple pneumoconiosis with bronchitis that between TPD and FEV 1 was calculated. The only significant correlation found was that between TPD and height $(r=0 \cdot 27, S D=0 \cdot 0585)$.

In Table I, the simple pneumoconiosis patients are grouped into those with and those without bronchitis. The non-smokers of the latter are a third group. The mean values and standard deviations of TPD and of height are shown for the three groups. There are no significant differences between any of the means.

Table II shows the mean values of TPD and of height in patients with complicated pneumo- 


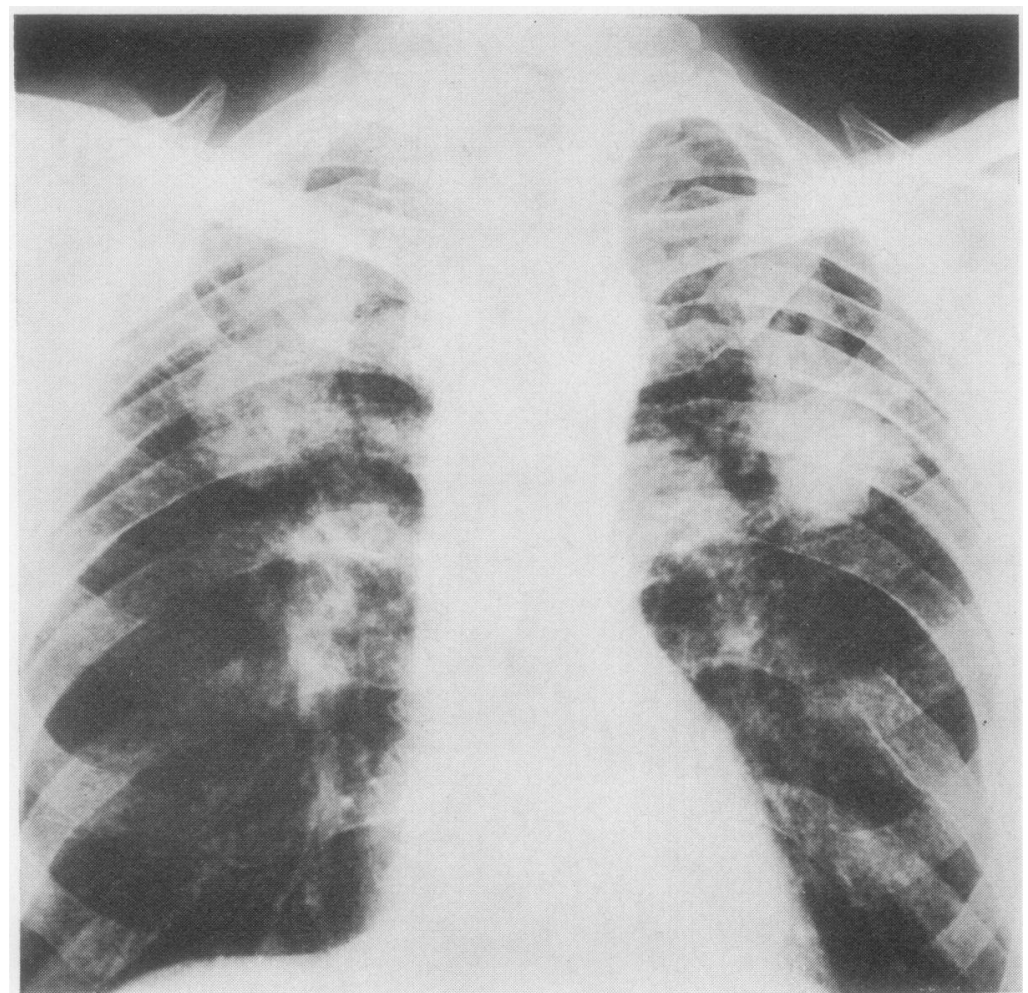

FIG. 2. Complicated pneumoconiosis with massive fibrosis : hilar structures retracted.

T A B LE I

MEAN VALUES OF HEIGHT AND TRANSPULMONARY ARTERY DISTANCE IN PATIENTS WITH SIMPLE

\begin{tabular}{|c|c|c|c|c|}
\hline & \multicolumn{2}{|c|}{ Height $(\mathrm{cm})$} & \multicolumn{2}{|c|}{ TPD (cm) } \\
\hline & Mean & SD & Mean & SD \\
\hline $\begin{array}{l}\text { Patients without bronchitis: } \\
\text { Smokers and non-smokers } \\
\text { (n=293) } \\
\text { Patients without bronchitis: } \\
\text { Non-smokers } \\
\text { ( } n=52) \\
\text { Patients with bronchitis } \\
(n=98)\end{array}$ & $\begin{array}{l}172 \cdot 19 \\
171 \cdot 73 \\
171 \cdot 12\end{array}$ & $\begin{array}{l}5 \cdot 18 \\
5 \cdot 69\end{array}$ & $\begin{array}{l}10 \cdot 34 \\
10 \cdot 31\end{array}$ & 0.81 \\
\hline
\end{tabular}

coniosis. In the living patients, the group with $\mathrm{C}$ shadows has a mean TPD significantly greater than that in the group with B shadows, which in the latter is significantly greater than in the group with A shadows, the differences being respectively 3.5 and 5.5 times the standard errors. The mean value in the patients with A shadows is not significantly different from those in the groups with simple pneumoconiosis in Table I. The patients who had B or C radiographic shadows and in
T A B L E I I

MEAN VALUES OF TRANSPULMONARY ARTERY DISTANCE AND HEIGHT IN PATIENTS WITH COMPLICATED PNEUMOCONIOSIS

\begin{tabular}{|c|c|c|c|c|c|c|}
\hline & \multicolumn{6}{|c|}{ Radiographic Classification } \\
\hline & \multicolumn{2}{|c|}{$\mathbf{A}$} & \multicolumn{2}{|c|}{ B } & \multicolumn{2}{|c|}{$\mathbf{C}$} \\
\hline & Mean & SD & Mean & SD. & Mean & SD \\
\hline $\begin{array}{l}\text { TPD }(\mathrm{cm}) \\
\text { Live patients } \\
\quad(n=367) \\
\text { Deceased: all patients } \\
\quad(n=155) \\
\text { Deceased: right } \\
\text { ventricular } \\
\text { hypertrophy } \\
\quad(n=87)\end{array}$ & $\begin{array}{c}10 \cdot 38 \\
(164) \\
-\end{array}$ & $\begin{array}{c}0.89 \\
-\end{array}$ & $\begin{array}{c}11.02 \\
(112) \\
11.27 \\
(56) \\
11.22 \\
(29)\end{array}$ & $\begin{array}{l}0.99 \\
0.90\end{array}$ & $\begin{array}{c}11 \cdot 45 \\
(91) \\
11 \cdot 77 \\
(99) \\
\\
11 \cdot 84 \\
(58)\end{array}$ & $\begin{array}{l}0.79 \\
0.99\end{array}$ \\
\hline $\begin{array}{l}\text { Height }(\mathrm{cm}) \\
\text { All patients } \\
\quad(\mathrm{n}=522)\end{array}$ & $\begin{array}{c}171 \cdot 17 \\
(164)\end{array}$ & $5 \cdot 80$ & $\begin{array}{c}170 \cdot 61 \\
(168)\end{array}$ & $5 \cdot 04$ & $\begin{array}{c}171 \cdot 25 \\
(190)\end{array}$ & $4 \cdot 98$ \\
\hline
\end{tabular}

whom complicated pneumoconiosis was a material factor in causing death are also grouped in Table II. In those with $C$, but not in those with $B$, shadows the mean TPD is significantly greater than in the living patients with similarly classified films; but there is no significant increase in TPD in those 
found at necropsy to have right ventricular hypertrophy. The mean height of each radiological group of complicated pneumoconiosis is less than that of the patients with simple pneumoconiosis without bronchitis, but only in the patients with $B$ and $C$ shadows is the difference statistically significant.

\section{DISCUSSION}

An entirely satisfactory control group was not available in this study and the TPD measurements of the patients with simple pneumoconiosis without chronic bronchitis are taken as a basis for comparison. In these, as in the normal subjects in the investigation of Hicken et al. (1968), a positive correlation was found between TPD and height. The absence of correlation between stem-height and TPD probably arises from the difficulty in obtaining accurate measurements of the former (Ferris and Stoudt, 1971).

Hicken and his colleagues found no correlation of TPD with total lung capacity and we found none with forced expiratory volume. The mean TPD in the normal subjects reported by these authors $(8.76 \mathrm{~cm}, \mathrm{SD} 0.81 \mathrm{~cm})$ is lower than that in our simple pneumoconiosis patients, but the age and sex distribution of the two groups is considerably different. Their chronic bronchitis group, however, with a similar age and sex distribution, has a TPD value $(10.26 \mathrm{~cm}$, SD $1.08 \mathrm{~cm})$ closely similar to that in the groups in Table I.

The shorter stature found in the patients with pneumoconiosis and massive fibrosis has been evident in other investigations (Gilson and HughJones, 1955 ; Cochrane, 1962). Since it is positively correlated with height the real increase in TPD in the patients with $B$ and $C$ radiographic shadows may well be more than that indicated in Table II.

The increased TPD found with advanced massive fibrosis reflects the pulmonary hypertension which is present in such patients (Thomas, 1951; James and Thomas, 1956 ; Gough, 1965). Massive fibrosis is accompanied by severe obliterative and destructive changes in large and small pulmonary vessels: in simple pneumoconiosis vascular changes are slight (Gough, 1953 ; Wells, 1954). Harvey and Ferrer (1960) found emphysema to be a constant concomitant of complicated pneumoconiosis and considered that anoxia, as well as anatomical lesions, contributed in varying proportion to the production of cor pulmonale. In simple pneumoconiosis raised pulmonary artery pressure is rarely detected (Lapp et al., 1971) and right ventricular hypertrophy is not a feature (Gilson and HughJones, 1955 ; Gough, 1965 ; Reid, 1967): mean TPD in such cases would be expected to lie within the range of normality.

In preparing this article I am indebted to Dr. J. Watkins-Pitchford, Chief Medical Adviser, Department of Health and Social Security, for encouragement as well as for permission to make use of panel records and radiographs.

\section{REFERENCES}

Ciba Guest Symposium (1959). Terminology, definitions, and classification of chronic pulmonary emphysema and related conditions. Thorax, 14, 286.

Cochrane, A. L. (1962). The attack rate of progressive massive fibrosis. Brit. J. industr. Med., 19, 52.

Ferris, B. G., and Stoudt, H. W. (1971). Correlation of anthropometry and simple tests of pulmonary function. Arch. environm. Hlth, 22, 672.

Gilson, J. C., and Hugh-Jones, P. (1955). Lung function in coalworkers' pneumoconiosis. Spec. Rep. Ser. med. Res. Coun. (Lond.), 290. H.M.S.O., London.

Gough, J. (1953). Diseases of the lung. In: Recent Advances in Pathology, edited by G. Hadfield, 6th ed. Churchill, London.

- (1965). Pathological changes in the lungs associated with cor pulmonale. Bull. N. Y. Acad. Med., 41, 927.

Harvey, R. M., and Ferrer, M. I. (1960). A clinical consideration of cor pulmonale. Circulation, 21, 236.

Hicken, P., Green, I. D., and Bishop, J. M. (1968). Relationship between transpulmonary artery distance and pulmonary arterial pressure in patients with chronic bronchitis. Thorax, 23, 446.

International Labour Office (1970). International Classification of Radiographs of Pneumoconiosis. Occupational Safety and Health Series, 22. International Labour Office, Geneva.

James, W. R. L., and Thomas, A. J. (1956). Cardiac hypertrophy in coalworkers' pneumoconiosis. Brit. J. industr. Med., 13, 24.

Lapp, N. L., Seaton, A., Kaplan, K. C., Hunsaker, M. R., and Morgan, W. K. C. (1971). Pulmonary hemodynamics in symptomatic coal miners. Amer. Rev. resp. Dis., 104, 418.

Milne, E. N. C. (1963). Physiological interpretation of the plain radiograph in mitral stenosis, including a review of criteria for the radiological estimation of pulmonary arterial and venous pressures. Brit. J. Radiol., 36, 902.

Moore, C. B., Krauss, W. L., Dock, D. S., Woodward, E., and Dexter, L. (1959). The relationship between pulmonary arterial pressure and roentgenographic appearance in mitral stenosis. Amer. Heart J., 58, 576.

Reid, L. (1967). The Pathology of Emphysema. Lloyd-Luke, London.

Thomas, A. J. (1951). Right ventricular hypertrophy in the pneumoconiosis of coalminers. Brit. Heart J., 13, 1 .

Wells, A. L. (1954). Pulmonary vascular changes in coalworkers' pneumoconiosis. J. Path. Bact., 68, 573. 